\title{
Damage Detection in Sandwich Composites Using Damping Matrix Identification
}

\author{
Frederick Just, Basir Shafiq', David Serrano, Marilu Ortiz \\ School of Engineering, University of Puerto Rico, Mayagüez, PR 00681
}

\begin{abstract}
A semi-empirical iterative computational algorithm along with data obtained from modal analysis is presented to identify the damping matrix and hence a means to quantify FRF changes associated with damage in sandwich composites. Mode shapes, damping ratios and natural frequencies were derived from experimentally obtained FRF's, while mass and stiffness matrices were obtained from FEA in order to formulate the damping matrix. The algorithm was initially tested on a simple two-degree of freedom lumped mass system and later sandwich composite and aluminum beams were tested for undamaged and the damaged cases. Comparison of analytical and empirical FRF plots demonstrated successful correlation. It was concluded that the damping matrix and updated FRF plots obtained through this computational algorithm can be adequately used to represent the structural damage characteristics.
\end{abstract}

Key Words: Damping Matrix, FRF Modeling, Sandwich Composites

\section{INTRODUCTION}

Assessing integrity of sandwich composite structures using vibration and damping analysis has broad potential applications in aerospace, marine, civil and mechanical engineering fields. Substantial work has been conducted in the area of damage detection in homogeneous materials; however, most of the vibration based research has been limited to changes in natural frequencies, mode shapes, frequency response function (FRF), modal energy, sensitivity minimization, non-linear perturbation and curvature difference, etc. $/ 1-11 /$. In the reported literature, damage is generally simulated as a reduction in stiffness, whereas, research on damping as a damage indicator is scarce /12,13/. A common feature among most reported models is an assignment of an a priori value to damping in order to carry out the mathematical formulation. However, it is

\footnotetext{
' Corresponding Author: Phone: 787-832-4040 ext. 2094, Fax: 787-265-3816, Email: abasir@uprm.edu
} 
well known that damping characteristics are quite sensitive to the changes in the structural properties as various studies have reported damping to be a better indicator of damage than the stiffness changes /12-15/. However, damping matrix identification of materials is a challenging process especially in complex heterogeneous material systems where damping characteristics become highly dependent upon microstructure and compatibility among the constituents becomes a sensitive issue. This is particularly true of foam core/stiff facesheet sandwich composites used in this study $/ 4,10 /$.

While analytical techniques vary in their mathematical setup, they are generally based on comparison between damaged and undamaged states in which damage is simulated as a gap, hole, crack, or reduced stiffness element. In general, the level of success in most of the reported results has to be viewed in light of computational complexity and robustness in real life structural applications. In this paper, the damping matrix for the undamaged and the damaged cases is identified for a sandwich composite beam using an updated damping matrix identification iterative algorithm that is based on analytical mass and stiffness matrices and experimentally obtained natural frequencies, mode shapes and damping ratios. The damping matrix thus obtained along with reduced stiffness and mass matrices are also used to model the FRF's to compare damaged and undamaged cases. This model should adequately describe the dynamic behavior or the vibration response of the structure under excitation forces to ascertain damage information. The work is significant as it is based on analytical damping characteristics applied to sandwich composites, which is nonexistent in the literature. The damping matrix identification method is verified with numerical and experimental examples.

\section{MATERIAL PROPERTIES}

Sandwich composite beams made of two face sheets and a core material were used in this study. The face sheets were composed of one layer, 161g plain weave epoxy matrix carbon fiber, whereas the core material was a $6.0 \mathrm{~mm}$ urethane foam filled kraft paper honeycomb, as depicted in Fig. 1. The Young's modulus and mass per unit length for composite beams were obtained experimentally. The load-deflection curves for sandwich composite tested are shown in Fig. 2. Additionally, 6061-T6-Al specimens were tested for verification purpose. Material properties along with the dimensions of the beams are provided in Table 1. Three specimens of each type were tested. Damage was induced by drilling an $8 \mathrm{~mm}$ diameter hole at $1 / 3^{\text {rd }}$ the length from the fixed support in all beams.

\section{DAMPING MATRIX AND FRF MODELING}

Modeling techniques can be divided into discrete or continuous parameter methods. In general a continuous model better represents the behavior of a dynamic system $/ 14,16 /$. However the equations of 

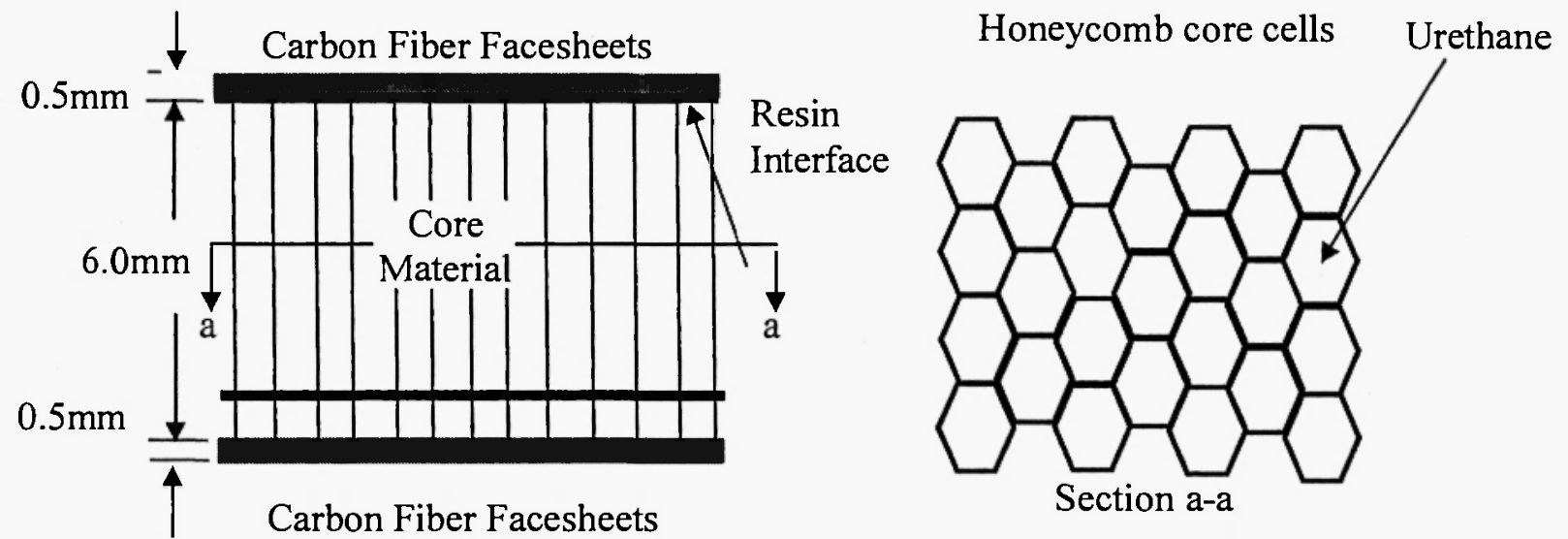

Fig. 1: Sandwich composite structure

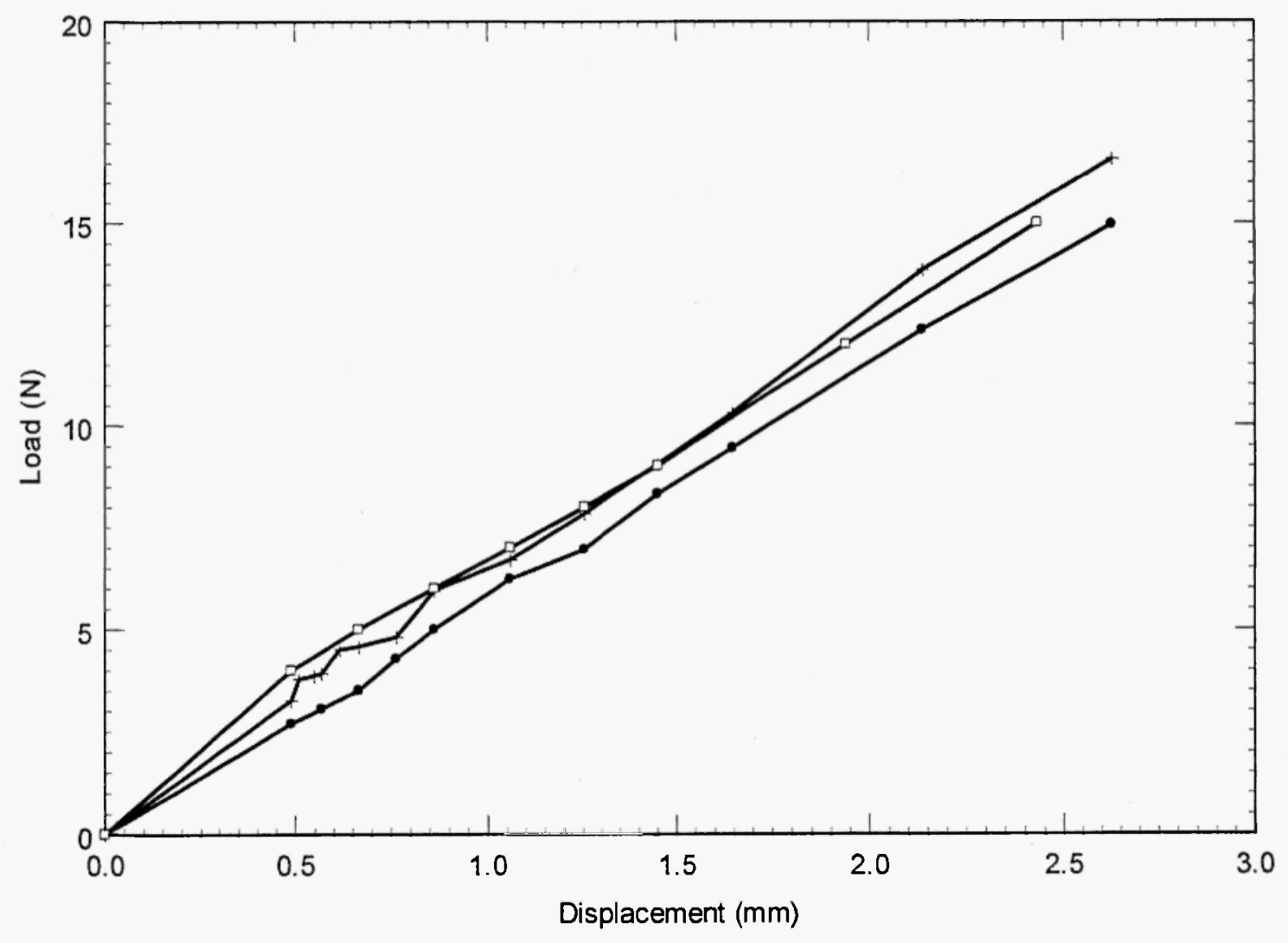

Fig. 2: Load-displacement behavior of sandwich composites 
Table 1

Specimen physical properties

\begin{tabular}{|l|l|l|l|l|}
\hline Material Property & Aluminum & $\begin{array}{l}\text { Sandwich } \\
\text { Composite 1 }\end{array}$ & $\begin{array}{l}\text { Sandwich } \\
\text { Composite 2 }\end{array}$ & $\begin{array}{l}\text { Sandwich } \\
\text { Composite 3 }\end{array}$ \\
\hline Length (m) & 0.4572 & 0.606425 & 0.605631 & 0.606425 \\
\hline Thickness (m) & 0.0047625 & 0.006951 & 0.006875 & 0.006875 \\
\hline Width (m) & 0.0254 & 0.051329 & 0.049742 & 0.051858 \\
\hline Mass (Kg) & 0.149 & 0.113322 & 0.106123 & 0.115044 \\
\hline $\begin{array}{l}\text { Young's Modulus } \\
\text { (GPa) }\end{array}$ & 69.0 & 7.2 & 7.6 & 7.3 \\
\hline
\end{tabular}

motion of a continuous system can be difficult or sometimes impossible to solve in a closed form. Therefore, in the majority of cases, dynamic analysis of engineering structures must rely on a representation of the structure by discrete parameter models and this is the technique that has been adopted in the current investigation. A beam can be described as a system with distributed stiffness, mass and inertia forces. It was assumed that mass, stiffness and damping properties do not vary with time and deformations of the structure are small and follow a linear stress-strain relationship before and after damage have occurred. When the foregoing assumptions are made, the structure being analyzed is said to be linear and the principle of superposition is valid which allows considerable simplification in the analysis. To ensure that the above assumptions held, Euler Bernouli beams were selected for analysis.

\section{Experimental Modal Analysis}

Experimental modal analysis seeks to find the structural modal properties such as, natural frequencies, mode shapes and damping ratios from FRF analysis. Whereas, an FRF [H(jw)] is a complex transfer function of the system in the frequency domain that represents the vibration response at a measured location on the beam, (a DOF), caused by an applied force at a specific known location, another DOF. This type of response function is usually graphed experimentally in a Bode diagram format where the peak values correspond to resonance $(\omega=\mathrm{k} / \mathrm{m})$ when the driving frequency is equal to the natural frequency. Mathematically, $[\mathrm{H}(\mathrm{j} \omega)]$ is an element of the matrix equation given as:

$$
\{H(j \omega)\}=\left\{\left([K]-[M] \omega^{2}\right)+([C] j \omega)\right\}^{-1}
$$

where $[\mathrm{K}],[\mathrm{M}],[\mathrm{C}]$ and $\omega$ represent the stiffness, mass and damping matrices and driving frequency, respectively. 
In the current study, each beam was divided into four sections and randomly vibrated on a $40 \mathrm{lbf}$ electromagnetic shaker before and after the induced damage to obtain FRF's. Shaker input was measured with a force transducer and the output response (displacements) in each of the four sections of the beam was measured using a laser vibrometer whose signal was electronically integrated using the dynamic signal analyzer. The signal analyzer performed data acquisition of the input and output signals and generated the experimental FRF used in the algorithm. The natural frequencies, $\omega_{1}$, were obtained directly from the experimental FRF plots and the damping ratios, $\zeta_{i}$, were calculated using the half-band-power method for each section following Eq. 2

$$
\zeta_{i}=\left(\omega_{b}-\omega_{a}\right) / 2 \omega_{i}
$$

where $\omega_{\mathrm{a}}$ and $\omega_{\mathrm{b}}$ are the frequencies located at $-3 \mathrm{db}$ from the natural frequency, $\omega_{\mathrm{i}} .15,16 /$. The average results for each beam are shown in Table 2.

Table 2

Specimen modal properties

\begin{tabular}{|c|l|l|l|l|l|l|l|l|}
\hline $\begin{array}{c}\text { Modal } \\
\text { Properties }\end{array}$ & \multicolumn{2}{|l|}{ Aluminum } & \multicolumn{2}{l|}{$\begin{array}{l}\text { Sandwich } \\
\text { Composite 1 }\end{array}$} & \multicolumn{2}{l|}{$\begin{array}{l}\text { Sandwich } \\
\text { Composite 2 }\end{array}$} & \multicolumn{2}{l|}{$\begin{array}{l}\text { Sandwich } \\
\text { Composite 3 }\end{array}$} \\
\hline & $\mathrm{U}$ & $\mathrm{D}$ & $\mathrm{U}$ & $\mathrm{D}$ & $\mathrm{U}$ & $\mathrm{D}$ & $\mathrm{U}$ & $\mathrm{D}$ \\
\hline$\omega_{1}(\mathrm{hz})$ & 19.0 & 18.8 & 16.7 & 16.8 & 17.4 & 13.3 & 16.9 & 16.9 \\
\hline$\omega_{3}(\mathrm{hz})$ & 119.5 & 118.9 & 104.3 & 104.4 & 106.4 & 104.4 & 105.6 & 105.6 \\
\hline$\omega_{3}(\mathrm{hz})$ & 334.2 & 333.9 & 285.0 & 286.9 & 292.4 & 276.5 & 289.0 & 288.8 \\
\hline$\omega_{4}(\mathrm{hz})$ & 654.5 & 655.4 & 540.1 & 542.5 & 554.7 & 542.8 & 548.5 & 547.5 \\
\hline$\zeta_{1}$ & .0013 & .002 & .0049 & .004 & .0055 & .0121 & .0042 & .0040 \\
\hline$\zeta_{2}$ & .00091 & .0007 & .0040 & .0038 & .0042 & .0062 & .0036 & .0036 \\
\hline$\zeta_{3}$ & .00067 & .0004 & .0039 & .0040 & .0039 & .0044 & .0037 & .0037 \\
\hline$\zeta_{4}$ & .00061 & .0003 & .0048 & .0051 & .0042 & .0046 & .0041 & .0043 \\
\hline
\end{tabular}

Note: $\omega_{i}$ and $\zeta_{i}$ represent natural frequency and damping ratios, respectively. $U$ and $D$ stand for damaged and undamaged cases.

\section{Finite Element Analysis (FEA)}

Once the damping ratios were known from modal analysis, FEA was carried out to create the system mass and stiffness matrices. However, difficulty arises as FEA takes into account rotational and translational degrees of freedom. Even with significant improvement in FRF measurement techniques, rotational DOF's are still difficult to measure accurately $/ 15,16 /$. 
Since only translational movements were measured experimentally, mass and stiffness matrices need to be made compatible with the DOF's used in the FRF plots. In order to achieve this, the Improved Iterative Reduction Scheme (IIRS) was invoked /14/. In this procedure, the mass and stiffness matrices are reduced by rearranging the locations of the matrix elements related to the master degrees of freedoms (the ones that are measured) and the slave degrees of freedom (the ones that are not measured), as shown in Eq. 3.

$$
\mathrm{M}=\left[\begin{array}{ll}
\mathrm{M}_{\mathrm{ntm}} & \mathrm{M}_{\mathrm{nis}} \\
\mathrm{M}_{\mathrm{sm}} & \mathrm{M}_{\mathrm{ss}}
\end{array}\right], \mathrm{K}=\left[\begin{array}{ll}
\mathrm{K}_{\mathrm{nim}} & \mathrm{K}_{\mathrm{nis}} \\
\mathrm{K}_{\mathrm{sm}} & \mathrm{K}_{\mathrm{s} \mathrm{s}}
\end{array}\right]
$$

where the subscript $\mathrm{m}$ refers to the master (measured) degrees of freedom, and $\mathrm{s}$ to the slave (unmeasured) degrees of freedom. The dynamic reduction of the system is determined using a transformation matrix, $\mathrm{T}_{\mathrm{i}}$, and a corrective term that is generated iteratively using the best estimate for the reduced model at each iteration, as given below,

$$
\mathrm{T}_{\mathrm{i}+1}=\left[\begin{array}{l}
I \\
t_{i+1}
\end{array}\right], \text { where } \mathrm{t}_{\mathrm{i}+1}=\mathrm{t}_{\mathrm{s}}+\mathrm{K}_{\mathrm{ss}}^{-1} / \mathrm{M}_{\mathrm{sm}} \mathrm{M}_{\mathrm{ss}} / \mathrm{T}_{i} \mathrm{M}_{\mathrm{Ri}}^{-1} \mathrm{~K}_{\mathrm{Ri}}
$$

with $t_{s}=-K_{s s}{ }^{-1} K_{s m}$. The reduced mass and stiffness matrices at the $i^{\text {th }}$ iteration are then obtained as, $M_{R i}=$ $T_{i}^{T} M T_{i}$ and $K_{R i}=T_{i}^{T} K T_{1}$. This analysis produces matrices with elements that are compatible to the master degrees of freedom used.

IIRS is more accurate than the conventional Guyan's reduction as in the latter method the original connectivity between DOF's is completely distorted after the reduction and as a result, it becomes impossible to accurately locate DOF's where damage has occurred $/ 13,14 /$.

\section{Damping Matrix Algorithm}

The intention of this investigation is to offer a methodology that can be efficiently used to identify damping matrix for complex material systems, such as, sandwich composites. The reduced mass and stiffness matrices and natural frequency, damping ratio, and mode shapes are utilized in the iterative updated algorithm to develop damping matrix as shown in the flow chart given in Fig. 3.

Development and verification of damping matrices is a very difficult and computationally intensive process $/ 12,13,17 /$. Therefore, the algorithm was initially tested on a two DOF lumped mass system shown in Fig. 4 for verification purpose. The governing differential equations for this system can be easily obtained. The methodology was to assign known values to mass, stiffness and damping matrices and to calculate modal parameters utilizing conventional modal analysis formulations; the results are shown in Table $3 / 16 /$. It should be noted that the eigenvalues are complex conjugate pairs; the damping algorithm, however, requires only one of them to proceed. To verify the methodology presented in Fig. 3, the modal parameters thus obtained (eigenvalues, eigenvectors and the mass matrix) were used as an input in the algorithm. Table 4 

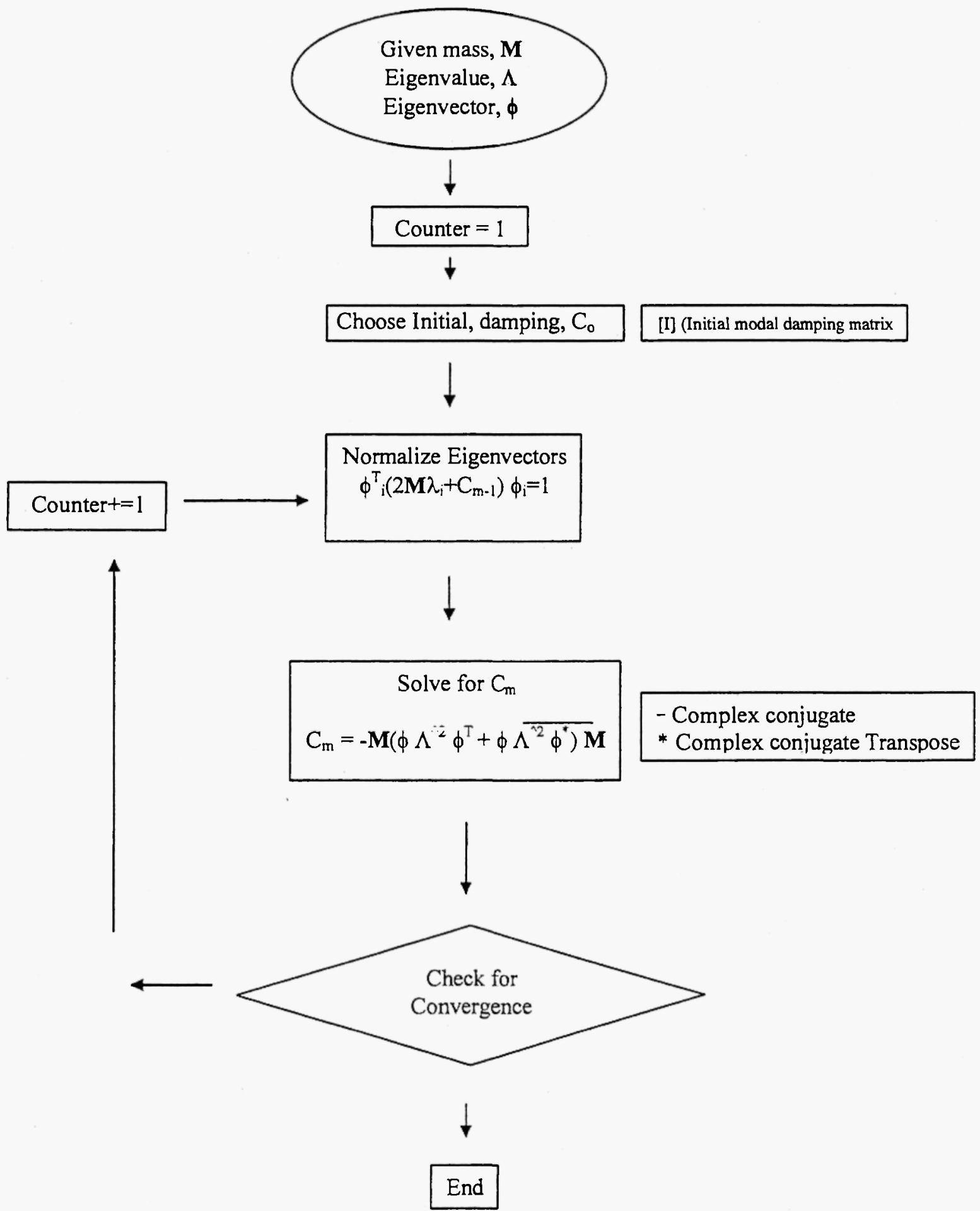

Fig. 3: Updated damping matrix identification algorithm 


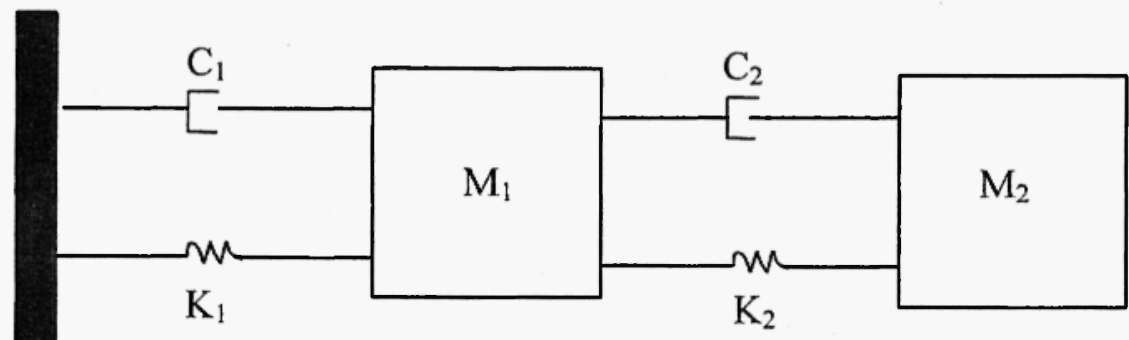

Fig. 4: Lumped mass two DOF model

Table 3

Two DOF example mass, damping and stiffness, eigenvalues and eigenvectors

\begin{tabular}{|l|}
\hline Mass Matrix $(\mathrm{Kg}),[M]=\left[\begin{array}{ll}5 & 0 \\
0 & 5\end{array}\right]$ \\
\hline Damping Matrix $(\mathbf{N} . \mathbf{s} / \mathbf{m}),[C]=\left[\begin{array}{cc}0.02 & -0.01 \\
-0.01 & 0.01\end{array}\right]$ \\
\hline Stiffness Matrix $(\mathbf{N} / \mathbf{m}),[K]=\left[\begin{array}{cc}3 & -1.5 \\
-1.5 & 1.5\end{array}\right]$ \\
\hline Eigenvalues $(\lambda$ - conjugate pairs) and Eigenvectors $(\Phi)$ \\
$\lambda_{\mathrm{I}}=-0.00038197+0.33851 i$ \\
$\Phi=\left[\begin{array}{cc}0.49797+1.2495 e-17 i & -0.63662 \\
0.80574 & 0.39345-1.8215 e-17 i\end{array}\right]$
\end{tabular}

Table 4

Damping matrix results for two DOF lumped mass system (of Fig. 4) obtained from algorithm presented in Fig. 3.

\section{Damping matrix after ten and twenty iterations}

$C_{10}=\left[\begin{array}{cc}0.020918 & -0.010028 \\ -0.010028 & 0.01089\end{array}\right]$ 
shows convergence within ten iterations to the exact solution. Several examples were run with arbitrary initial damping values and in every case the solution converged within twenty iterations to the exact solution. This verification provided the necessary confidence as to the accuracy of damping matrices obtained for $\mathrm{Al}$ and sandwich composite beams.

Following the algorithm of Fig. 3, typical results of the damping matrices of $\mathrm{Al}$ and sandwich composite damaged and undamaged beams are provided in Table 5. As can be seen, the damping matrix changes substantially as a result of induced damage. Therefore, the algorithm provided in Fig. 3 offers an efficient way to establish damping matrices for complex structures. However, it remains a challenge to quantify damage from damping matrix changes alone. Nevertheless, it is quite clear that it would be inaccurate to simulate damage as a stiffness reduction only and assign a fixed value to damping, as it has generally been presented in the literature $/ 1-11 /$.

Table 5

Typical damping matrices for damaged and undamaged cases of aluminum and sandwich composite beams obtained from algorithm presented in Fig. 3.

\begin{tabular}{|c|c|c|c|c|c|c|}
\hline \multirow{5}{*}{$\mathrm{C}_{\text {Aluminum }}$} & \multicolumn{2}{|l|}{ Undamaged } & \multicolumn{4}{|c|}{ Damaged } \\
\hline & $\begin{array}{lll}-1.90 & -2.22 & -3.72\end{array}$ & -2.41 & 4.89 & 4.79 & 3.43 & 1.34 \\
\hline & $-2.22 \quad-5.16 \quad-4.94$ & -2.21 & 4.79 & 4.98 & 7.60 & 2.15 \\
\hline & $\begin{array}{lll}-3.72 & -4.94 & 1.01\end{array}$ & -1.47 & 3.43 & 7.60 & 2.40 & -.16 \\
\hline & $\begin{array}{lll}-2.41 & -2.21 & -1.47\end{array}$ & -2.19 & 1.34 & 2.15 & -.16 & -.52 \\
\hline \multirow{4}{*}{$\mathrm{C}_{\text {Sandwich Composite }}$} & $\begin{array}{llll}-.25 & -.16 & .10 & .03\end{array}$ & & -.63 & -.20 & -.02 & -.12 \\
\hline & $-.16 \quad .07$ & & -.20 & .14 & -.12 & -.12 \\
\hline & $\begin{array}{ll}-.05 & .04\end{array}$ & & -.02 & -.12 & .69 & .29 \\
\hline & $.04 \quad .03$ & & -.12 & -.12 & .29 & .14 \\
\hline
\end{tabular}

\section{FRF Generation}

With the analytical damping, mass and stiffness matrices calculated, the FRF plots were regenerated and compared with the experimental FRF's. This comparison was performed to evaluate the adequacy of the damping matrix in generating accurate dynamic information. The representative model and experimental FRF plots for the damaged and undamaged cases are presented in Figs. 5 and 6 for the Al and sandwich composite beams, respectively. Fig. 5 (Al) shows an appreciable magnitude shift in both the model and experimental FRF plots due to the input magnitude that was used to produce the modal graphs. Little information is obtained directly by merely observing the damaged and undamaged FRF's; small frequency shifts and apparently small changes in modal damping. On the other hand, changes in FRF behavior between damaged and undamaged cases are far less pronounced in sandwich composites (Fig. 6), which was expected due to very high damping characteristics of foam core $/ 4 /$. 


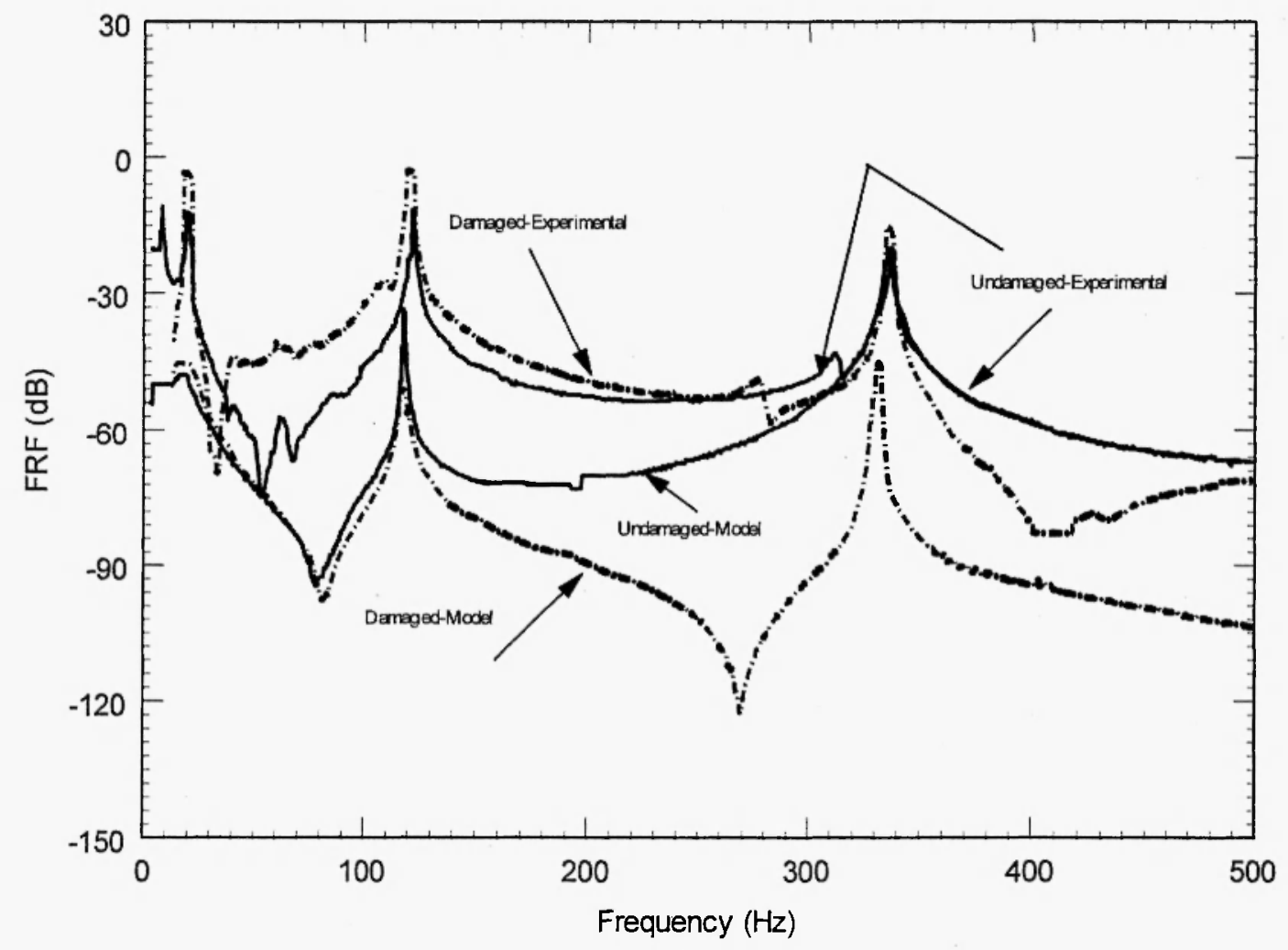

Fig. 5: Comparison of experimental and model based FRF's for damaged and undamaged Al beams.

In all of the cases, the error in the second and third natural frequencies between the experimental FRF and the modeled FRF was observed to be less than $10 \%$. However, for the first natural frequency an error of up to $21 \%$ was noticed even though coherence calculation yielded adequate values around the first natural frequency. This error is believed to be mainly due to equipment resolution issues around the value of the first natural frequency. The force transducer used was close to its operating limits and as a result more noise is present in the data at this lower frequency /18/. Furthermore, the magnitude of the forcing function was not recorded during the experiment, whereas a unit impulse was assigned to the model FRF calculation. Thus the 'difference in the frequency response magnitudes observed between the calculated and experimental FRF's could be due to unequal inputs which would alter the FRF magnitude. An additional source of error may be the presence of torsional modes that were clearly observed (but not accounted for in the analysis), thus producing some error in the transverse vibrations data for these cases. As mentioned earlier, the FRF model developed only considered transverse vibration of the structure. The use of a force transducer with higher resolution and better control of the forcing function can alleviate the problem to some extent; however, incorporation of torsional modes into the algorithm remains a challenge. 


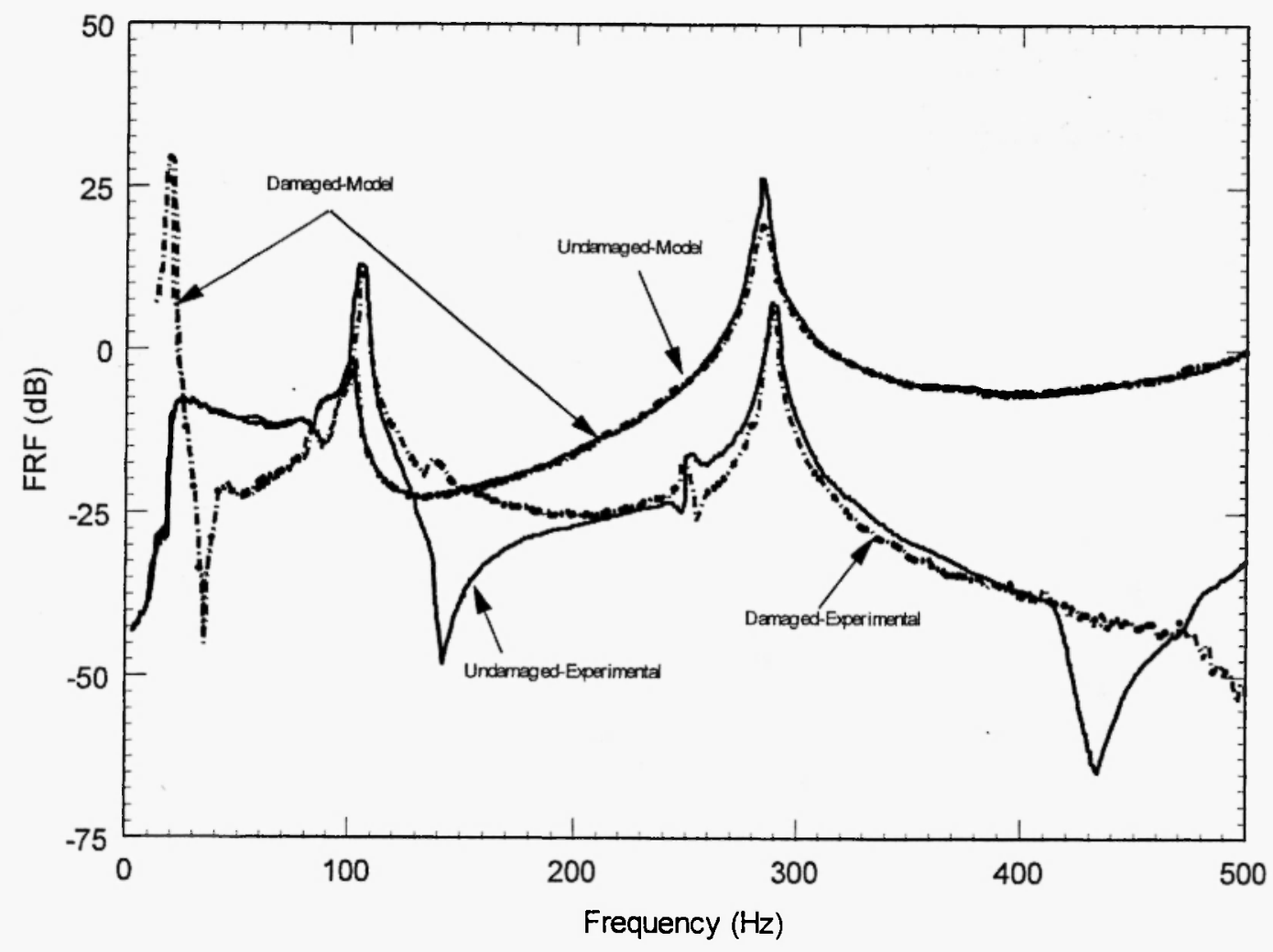

Fig. 6: Comparison of experimental and model based FRF's for damaged and undamaged sandwich composite beams.

\section{CONCLUSIONS}

There are a number of technical difficulties involved in modeling the dynamic behavior of a sandwich composite structure, such as, complex FRF data due to damping, noise in the FRF data, DOF's incompatibility (therefore model reductions) and material properties, etc. However, this research has demonstrated that the damping matrix of a sandwich composite can be estimated as long as the basic assumptions of linear behavior and symmetric damping matrix are met. The percentage differences between the FRF's obtained experimentally and the ones from the analytical models were within an acceptable margin and can be further improved by increasing the equipment accuracy at lower frequencies, and by increasing the model DOF's. Care should be taken with the type of damage induced to the structure since the structure can become non-linear and a significant frequency shift and amplification of torsional modes may occur. 


\section{ACKNOWLEDGMENTS}

The authors wish to acknowledge the authorities at ONR-Composites' for Marine Structures division for their financial support for this work. Special thanks are due to Dr. Yapa Rajapakse, the ONR program manager for his unrelenting support and guidance.

\section{REFERENCES}

1. D. Cappechi and F. Vestroni, Monitoring of structural systems by using frequency data, Earthquake Engineering and Structural Dynamics, 28, 447-461 (1999).

2. J. Kosmatka and J. Ricles, Damage detection in structures by modal vibration characterization, Journal of Structural Engineering, 125 (12), 1384-1392 (1999).

3. C. Ratcliffe and W. Bagaria, Vibration technique for locating delamination in a composite beam, AIAA Journal, 36 (6), 1074-1077 (1998).

4. M. Burnam, Fatigue behavior initiation and propagation in sandwich structures, Royal Institute of Technology, Report No. 98-29, ISSN 0280-4646, Sweden, 2000.

5. P. Cawley and R. Adams: The location of defects in structures from measurements of natural frequencies, Journal of Strain Analysis, 14 (2), 49-57 (1979).

6. M. Yuen: A numerical study of the eigenparameters of a damaged cantilever, Journal of Sound and Vibration, 103 (3), 301-310 (1985).

7. A. Pandey, M. Biswas and M. Samman: Damage detection from changes in curvature mode shapes, Journal of Sound and Vibration, 145 (2), 321-332 (1991).

8. J. Mackerle: Finite element analysis of sandwich structures: A bibliography (1980-2001), Engineering Computations, 19 (2), 206-245 (2002).

9. J. Collins, G. Hart, T. Hasselmen and B. Kennedy: Statistical identification of structures, AIAA Journal 12 (2), 185-190 (1974).

10. J. Kim, and Y. Ryu: Improved vibration-based damage detection algorithm for structures, Proceedings of the $17^{\text {th }}$ International Modal Analysis Conference, Feb 2-5, V1:889-895, 1999.

11. J. Lew, Using transfer function parameter changes for damage detection of structures, AIAA Journal, 33 (11), 2189-2193 (1995).

12. P. Lancaster: Expression for damping matrices in linear vibration problems, Journal of Aerospace Sciences, 1961, 256.

13. D. Pilkey: Computation of a damping matrix for finite element model updating, Thesis $\mathrm{PhD}$, Virginia Polytechnic Institute and State University, 1998.

14. M. Friswell and J. Mottershead: Finite Element Model Updating in Structural Dynamics, Kluwer Academic Publishers, Massachusetts, 1995. 
15. N. Mendes and J. Montalvo: Theoretical and Experimental Modal Analysis, John Wiley \& Sons, New York, 1992.

16. D. Inman: Engineering Vibration, Prentice-Hall Inc., New Jersey, 1994.

17. C. Minas and D. Inman: Identification of a nonproportional damping matrix from incomplete modal information, Journal of Vibration and Acoustics, 113, 219-224 (1991).

18. S. Alampalli, G. Fu and E. Dillon: Signal versus noise in damage detection by experimental modal analysis, Journal of Structural Engineering, 123 (2), 237-245 (1997). 
